\title{
Sátiras judiciales de Sancho y don Quijote

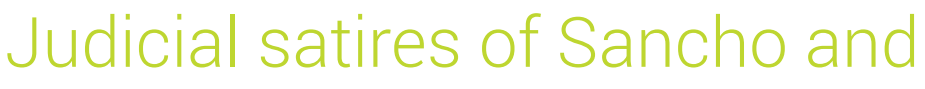 don Quijote
}

\section{Christoph Strosetzki}

Universität Münster

ALEMANIA

stroset@uni-muenster.de

[Hipogrifo, (issn: 2328-1308), 7.1, 2019, pp. 701-711]

Recibido: 29-03-2019 / Aceptado: 06-05-2019

DOI: http://dx.doi.org/10.13035/H.2019.07.01.51

Resumen. Las negociaciones por el yelmo de Mambrino en los capítulos 44 y 45 de la Primera parte de Don Quijote nos recuerdan a una corte. Ya al comienzo aparecen la demanda y la defensa cuando el barbero que ingresa a la posada, pidiendo ayuda al rey y a la justicia, llama a don Quijote «ladrón» y «salteador de caminos», mientras que Sancho emplea como defensa «que en buena guerra ganó mi señor don Quijote estos despojos». Además de esta conocida escena, parecida a un proceso judicial, existen los casos que Sancho debe resolver como gobernador y juez y el juicio divino, en el caso de la hija de don Rodríguez, el cual don Quijote, por ausencia de pruebas admisibles judicialmente, debe resolver en un duelo. Dado que en todas estas situaciones se trata de casos más o menos claros de procesos civiles o penales, se debe plantear la interrogante de cuál es el enfoque de la justicia. ¿ Juzga perspicaz y justamente o es tan ineficiente como las personas de la posada, que juzgaron sobre el yelmo de Mambrino, donde tuvo que llevarse adelante un acuerdo extrajudicial?

Palabras clave. Yelmo de Mambrino; corte; justicia; proceso judicial; Sancho como juez; acuerdo extrajudicial.

Abstract. The negotiations of the helmet of Mambrino in the chapters 44 and 45 of the first part of the Don Quijote already remind one of a court of justice. Lawsuit and defence already appear at the beginning when the barber, who enters the inn, asking the king and justice for help calls don Quijote a «thief» and «mugger», while Sancho is defending his master «who had won the booty in victorios battle». Besides this well-known scene, which strongly resembles a judicial process, there are other situations which Sancho has to solve as governor and judge, and trial by or- 
deal, in the case of don Rodríguez' daugther which don Quijote has to solve in duel due to missing admissble proof. For all these are more or less cases of civil and criminal processes, one has to figure out the role of justice. Is it prudent and just, or is it as inefficent as the people in the inn, who judge over the helmet of Mambrino pursuing a settlement out of court?

Keywords. Helmet of Mambrino; Court of justice; Justice; Judicial process; Sancho as judge; Settlement out of Court.

Ya las negociaciones por el yelmo de Mambrino en los capítulos 44 y 45 de la Primera parte de don Quijote nos recuerdan a una corte. Ya al comienzo aparecen la demanda y la defensa cuando el barbero que ingresa a la posada, pidiendo ayuda al rey y a la justicia, Ilama a don Quijote «ladrón» y «salteador de caminos», mientras que Sancho emplea como defensa «que en buena guerra ganó mi señor don Quijote estos despojos» (p. 568)'. El lector, que a partir de ahora toma el lugar del juez, sabe que la toma del botín es legítima en una guerra justa, pero que en el presente caso, en el que el barbero había huido sin luchar, no hubo un duelo justo entre don Quijote y el barbero. El hecho de si es robo o legítima toma de posesión depende de la definición del objeto: si es una bacía de barbero, entonces difícilmente será tomada en una pelea justa y don Quijote será culpable. Pero si es el yelmo de Mambrino, entonces es posible que haya sido tomado en una pelea justa y, ene se caso, don Quijote es inocente. O sea que existe incertidumbre en la pregunta de que si algo es, lo qué es y de qué tipo es, y por eso el barbero trae a colación la albarda de montar del burro, la cual, desde su perspectiva, también es robada, para demostrar que lo que es válido para la albarda de montar, es mucho más válido aún para la bacía del barbero. Como prueba propone que se ensille su mula con la albarda para comprobar qué tan justa le queda. Pero don Quijote confunde el proceso de prueba asegurando que también le permitió a Sancho, después que tomó el yelmo, tomar la silla del caballo, la cual por intervención de un mago se había convertido en una albarda para burros. Pero si hubo un cambio en la albarda de montar, esta ya no sirve como argumento a comparatione a favor del yelmo, lo que ve Sancho cuando dice: «Si no tenemos otra prueba de nuestra intención que la que vuestra merced dice, tan bacía es el yelmo de Mambrino como el jaez deste buen hombre albarda!» (p. 569).

Para don Quijote la albarda de montar del burro sigue siendo una montura de caballo, la bacía del barbero un yelmo y la posada un castillo. Se llega a un acuerdo extrajudicial con el barbero que fue robado: el cura le da sin conocimiento de don Quijote ocho reales, los cuales recibe, renunciando a otras reivindicaciones. Con una conciliación extrajudicial se da por terminado el litigio entre el barbero robado y Sancho: solamente la albarda cambiaría de dueño, no así las cinchas ni demás accesorios. Dado que el hecho depende del objeto en cuestión, cuya definición 
sigue siendo controvertida, no es posible decidir si don Quijote debe ser condenado como ladrón o si debe ser declarado inocente victorioso guerrero².

Además de esta conocida escena, parecida a un proceso judicial, existen los casos que Sancho debe resolver como gobernador y juez y el juicio divino, en el caso de la hija de don Rodríguez, el cual don Quijote, por ausencia de pruebas admisibles judicialmente, debe resolver en un duelo. Dado que en todos estos casos se trata de casos más o menos claros de procesos civiles o penales, se debe plantear la interrogante de cuál es el enfoque de la justicia. ¿Juzga perspicaz y justamente o es tan ineficiente como las personas de la posada, que juzgaron sobre el yelmo de Mambrino, donde tuvo que llevarse adelante un acuerdo extrajudicial?

Como se transforma la bacía del barbero para don Quijote en el yelmo de Mambrino, también se presenta un cambio en el primer caso, en el cual debe juzgar Sancho: las capuchas deseadas por el campesino se transforman en dedales. Como es habitual en un proceso civil, el campesino presenta como demandante su reclamo legal. Él quiere que el sastre le devuelva la tela que le entregó o bien una suma de dinero que equivalga a su valor.

Debería ser probada por el tribunal, en un proceso de reconocimiento, la fidelidad del reclamo del demandante tanto en los hechos como en el aspecto legal. El acusado, el sastre, podría solicitar la desestimación de la demanda total o parcialmente, podría impugnar algunas afirmaciones fácticas y argumentar por qué la presentación de los hechos desde su punto de vista es errónea. Pero él confirma los hechos presentados por el demandante y aduce como nuevo hecho que el campesino requiere de él primero una y finalmente cinco capuchas, para que no fuera a sobrar ningún trozo de tela que el sastre le pudiera robar. $Y$ mientras señala que el campesino no le pagó su jornal de mano de obra, a él, al sastre, este presenta una contrademanda, que él como acusado eleva contra el demandante. A la demanda de cumplimiento del campesino, quien pretende una indemnización por la tela cortada, se opone la demanda del sastre, quien pretende su jornal. Cuando el sastre finalmente muestra sus cinco dedales, proporciona una evidencia de su trabajo por inspección visual, que se sabe que se realiza a través de la percepción directa por parte del tribunal de hechos relevantes. Luego de la presentación y aceptación de pruebas el tribunal debería volver a debatir sobre los hechos y disputas sobre la base de los nuevos hallazgos.

Sería necesario aclarar en qué medida se daría lugar a una contrademanda o si se realizaría una compensación por las reclamaciones de las contrapartes. Al final, con el otorgamiento del pedido se cerró un contrato entre el campesino y el sastre, o sea, un acuerdo de voluntades entre dos personas con efecto jurídico. Este tipo de contrato existe en las relaciones legales si existen dos declaraciones de voluntad consensuadas. Pero entre el campesino y el sastre hay una falta de acuerdo, porque el primero no ha atendido ni al horizonte receptor ni a la diligencia interpretativa del sastre. En el sentido de la hermenéutica, el horizonte del receptor incluye el conocimiento de las circunstancias, el conocimiento de las reglas, el conocimiento 
de acciones previas y las circunstancias que las acompañaron, mientras que la diligencia interpretativa debe entenderse como los requisitos de cuidado y atención dirigidas al receptor. El principio «falsa demonstratio non nocet» no es aplicable porque no hay una comprensión convergente de las partes.

Ante la existencia de un contrato rige también la responsabilidad contractual con la obligación de una indemnización por la prestación contractual adeudada o esperada. La responsabilidad por daños presupone que el deudor es responsable por el incumplimiento de la obligación. Una obligación contractual produce un reclamo del acreedor. ¿Puede el campesino reclamar daños en lugar de la prestación completa, aunque el sastre haya generado un cumplimiento parcial? Además, ¿el campesino perjudicado es cómplice en la generación del daño, lo que puede conducir a la división de los reclamos o incluso a la cancelación del reclamo? Si se considera la suposición tal vez injustificada del robo del campesino al sastre, al campesino le corresponde una responsabilidad compartida. Como es la distribución real del porcentaje de daños depende entonces de la medida en que el autor del daño y la parte perjudicada estuvieron involucrados en el origen del daño. También se aplica una negligencia compartida de la parte perjudicada en aquellos casos en los que esta no alertó a la parte lesionante sobre el riesgo de que se produjera un daño o si omitió evitar el daño o reducirlo. La malversación de otro debe ser castigada, no la intención de enriquecerse, por lo que el hasta ahora caso civil se convierte en un caso penal.

El juez Sancho no parece haber reflexionado sobre tales consideraciones, porque el asunto no le parece tan complejo como para que requiriera de investigaciones más extensas. Él resuelve que el campesino pierda su tela y el sastre su jornal, con lo cual él contempla la culpabilidad contributiva de ambos. Sin embargo, el hecho de que un sastre corte dedales en lugar de una capucha se contradice con cualquier experiencia de vida y hace parecer el caso como improbable y al tribunal que sentencia seriamente el caso lo hace parecer como objeto de la sátira.

En la investigación, Sancho es visto, por un lado como un juez salomónico en su sentencia, por otro lado como «cuerdo loco» ${ }^{3}$ en el sentido del Elogio de la locura de Erasmo de Rotterdam. Ángel Pérez Martínez ve una mayor atención de Sancho y su enfoque en la percepción sensorial y la falta de la capacidad de aplicar principios generales a situaciones concretas ${ }^{4}$. Maravall aprecia en la gobernación de Sancho elementos utópicos ${ }^{5}$. Se enfatizó tanto el carácter carnavalesco como el folclórico ${ }^{6}$. Pelorson considera el trabajo de Sancho como juez en el contexto de la oposición de armas y letras, la cual en general se decide en Cervantes a favor de las armas y a expensas de las letras y de los letrados, convirtiéndose estos últimos en el tema de la sátira? ${ }^{7}$. Carmen Rivero ve con razón a Sancho como un gobernador que piensa 
subjetivamente sacrificarse por el bien común, lo que lo distingue de don Quijote ${ }^{8}$. Susan Byrne, también, ve al gobernador Sancho como tan desinteresado que puede decir que comenzó sin fortuna y acaba sin fortuna9 ${ }^{9}$. Hasta ahora Sancho como juez en sus juicios no ha sido reconocido en la investigación desde la perspectiva de la jurisprudencia. Por lo tanto, esto deberá intentarse en adelante.

En el segundo caso, un acreedor acusa a un deudor de negar que ha recibido las diez monedas de oro que ha tomado prestadas y asegura que las habría devuelto hace mucho tiempo si las hubiera recibido. Como no habría testigos, el deudor debe jurar ante el tribunal. Le da su bastón al acreedor para poder jurar mejor y jura haber devuelto en mano las monedas de oro al acreedor. Convencido de la honestidad del deudor, el acreedor cree ahora que se ha equivocado y que olvidó la devolución. Con esto parece haber finalizado el proceso. Pero antes de que se marchen las partes, el juez Sancho los llama y continúa con la obtención de evidencias rompiendo el palo y mostrando que en él se encontraban las diez monedas de oro que le entrega entonces al acreedor. Todos se maravillan de la sabiduría de Sancho en la ejecución de la prueba. Nadie menciona las consecuencias penales que resultan del proceso.

Desde su propia perspectiva y la del lector, el deudor ha dicho la verdad en su juramento. Sin embargo, desde la perspectiva del acreedor y del tribunal el juramento es un perjurio con la intención de engaño, abusando deliberadamente de la buena fe del demandante y del tribunal, deseando y sabiendo que su declaración llevará al engañado a un error, haciéndole creer en una devolución del dinero realizada hace mucho tiempo. Es un engaño porque el deudor despierta una falsa impresión por una acción concluyente. Dado que el deudor, con la intención de obtener una ventaja financiera ilegal, provoca un error por tergiversación y supresión de hechos reales, también existe el delito de intento de fraude, que debe ser procesado penalmente.

Como es sabido, a las personas sospechosas de estar involucradas en el delito objeto de la investigación, generalmente no se les toma juramento. Independientemente de la cuestión de si el juramento del acusado en el presente caso es una prueba admisible, el deudor incurrió en perjurio, que a su vez deberá ser procesado y castigado como un delito. Después de todo, un juramento es la garantía de que, según el leal saber y entender, se ha dicho la pura verdad y no se ha callado nada.

Como en el caso del yelmo de Mambrino, la pregunta de qué es un objeto depende de la perspectiva. Si el bastón era un bastón para todos los presentes, a excepción del deudor, es, al final, para todos, como previamente para el deudor, principalmente un depósito de dinero. Él ha sufrido un cambio originado por el sabio juez Sancho, por el cual ha presentado una prueba visual. La sabiduría de Sancho se manifiesta en la investigación de las pruebas, cuando expone el engaño del deudor y el tribunal engañado descubre el fraude. La comicidad surge del hecho de que se trata de un caso legal ambiguo, porque el deudor engaña diciendo la verdad. 
También en el tercer caso el juez Sancho se distingue especialmente en la obtención de la evidencia. Luego de que una mujer acusa a un campesino de violación, este responde que ella ha tomado dinero a cambio de sexo. Como no estaba satisfecha con el monto de dinero, lo había arrastrado ante la corte. Sancho decreta que el campesino debe entregar todo su dinero a la demandante, pero después de la partida de la mujer le pide al campesino que vuelva a tomar el dinero y regrese luego. Cuando el campesino regresa con la mujer, resulta que él no tenía la fuerza para dominar a la mujer, quedando demostrado a la vista que tampoco podía violarla. La presunta víctima de violación resulta ser una prostituta estafadora. El juez Sancho dicta sentencia, el campesino recupera su dinero y la mujer es desterrada de la isla. Esta vez Sancho castiga el intento de fraude, la declaración falsa deliberada, el juramento falso y la falsificación de un delito ante un tribunal. Quizás también quiera desterrar la prostitución de la isla, y aconseja al campesino que evite futuras acciones tan comprometedoras.

Sancho también quiere desterrar las casas de juego de la isla. El juez Sancho, quien se pasea ahora por la ciudad con su séquito, encuentra frente a una de los garitos de juego a dos personas peleando con espadas. Confrontado, el jugador acusa al otro del intento de robo y hurto, mientras que este último declara que ante situaciones dudosas en el garito de juegos él ha decidido como espectador a favor del jugador, en contra de un mejor conocimiento y conciencia, por lo cual este habría ganado mil reales. Sin embargo, no había recibido la importante propina de ocho reales que él esperaba, sino solo la suma de cuatro reales. Por eso había perseguido al jugador para exigirle enérgicamente los ocho reales. Como contrademanda, el sinvergüenza acusa al jugador de ser un ladrón, uno más grande que Caco, el ladrón asesino de la mitología romana, y además un tramposo peor que un tal Andradilla. El jugador responde que el hecho de que el acusado hubiera recibido solo la suma usual de cuatro reales sugiere que no debe ninguna retribución por asistencia en el juego tramposo. Sancho deja abierta la cuestión de si la ganancia fue legítima o no y sentencia que el jugador le dé ciento treinta reales al sinvergüenza, quien es desterrado inmediatamente de la isla.

La cuestión es si el bribón tiene derecho legal para exigir una propina y en base a qué puede reclamar una determinada cantidad. Dado que se trata de una dádiva voluntaria, no se puede hablar de deudas de juego, por las que de todos modos no sería posible hacer una reclamación, y se desestimarían por infundadas. El monto de la reclamación se basa en el monto de la ganancia, que corresponde al monto de la participación fraudulenta del bribón. Dado que el sinvergüenza la considera generosa pero el jugador la clasifica como baja, hay un desacuerdo. Como el juez Sancho decide que el jugador debe dar una propina de cien reales de los más de mil ganados en el juego, califica la participación fraudulenta como relativamente alta. Aparece como un tópico del mundo al revés ${ }^{10}, \mathrm{o}$ al menos como una sentencia injusta, si se ordena judicialmente un pago, sobre el cual no existe el derecho a una reclamación legal, que ejecutaron a través del poder de la espada y el cual que es una retribución a un fraude. El secretario de la corte considera el deseo de

10. Redondo considera a Sancho la «personificación del Carnaval» (1978, pp. 51, 63). 
Sancho de desterrar las casas de juego de la isla como factible para los garitos más pequeños, pero no así para las casas de juego más grandes, por las cuales circulan los nobles y los grandes caballeros. Por lo tanto, ¿deberá considerarse como una expresión de justicia de clase, si el juez Sancho destierra al bribón, que no tiene dinero ni profesión, pero deja ir al jugador calificado como «buen caballero» después del pago de aproximadamente un trece por ciento de su ganancia en el probablemente juego fraudulento?

También en los últimos tres casos se manifiestan más los límites que las capacidades de Sancho como juez. En el siguiente caso hay un enfrentamiento de poderes entre el juez y el acusado. Un muchacho es capturado por la policía y llevado ante el juez. Dado que se había escapado de las autoridades, existía una sospecha inicial de un delito. Él responde a las preguntas sobre su identidad con bromas y contradicciones que hacen que el juez se sienta provocado. Habría huido para ahorrarse preguntas innecesarias y habría estado fuera para recuperar el aliento. Cuando el juez ordena que duerma en la cárcel sin aire, el juicio se convierte en un enfrentamiento de poderes y el enfado por la falta de respeto del acusado hacia la corte provoca su reacción. O sea que Sancho no juzga con imparcialidad, sino desde las emociones, para ejemplarizar a través del hecho su poder. La respuesta del acusado muestra sistemáticamente los límites del poder judicial: no puede convertirlo en rey tan poco como obligarlo a dormir. Cuando Sancho responde que tiene la potestad de apresarlo o de dejarlo ir a su antojo, aparece esto como una arbitrariedad jurídica absolutista que no conoce las leyes. Sancho deja ir al muchacho recién después de que él haya declarado que no duerme por su propia voluntad y no porque quisiera atentar contra la voluntad judicial de Sancho. No ve que una cosa condiciona la otra, así como no ve el hecho que se ha mostrado más ridículo que sabio en su intento de demostración de poder. Incluso en el penúltimo caso, tampoco puede salir ileso. Otra vez alguien es detenido por la policía por huir. Primero es llevada ante el juez una chica bonita, luego su guapo hermano con una sospecha inicial de un delito. Sin embargo, resulta que la hermana, quien fue encerrada durante años por su padre, acompañada por su hermano, en secreto e inadvertida por su padre, quería ver la ciudad de noche, lo que desde el punto de vista judicial es tan legal como legítimo. Sin embargo, Sancho no duda en hacerse cómplice y asegurarse de que los dos sean escoltados a casa para regresar a tiempo y desapercibidos. Aquí es culpable de favoritismo, porque no hizo escoltar a nadie de los que desterró. El juez Sancho pierde completamente su imparcialidad cuando se propone casar al guapo hermano con su hija Sanchica.

El último caso de Sancho conduce al mundo de los cuentos, de la fantasía, donde todo es posible y todo es creíble. Esto se aplica tanto a los hechos como a la sentencia de Sancho, sobre todo porque es alabado como especialmente sabio y digno licúrgico. Cuatro jueces perplejos le solicitan consejo a Sancho, como instancia superior, en el presente caso. Cuando alguien cruza el puente sobre un río, tiene que declarar bajo juramento a dónde quiere ir y qué quiere hacer. Si dice la verdad, puede cruzar sin sufrir daño. Si miente, es colgado inmediatamente en la horca. Pero ahora ha llegado alguien que ha jurado que morirá en dicha horca. El dilema es: si lo dejan pasar, entonces ha hecho un falso juramento y debería morir. 
Si lo cuelgan, entonces ha dicho la verdad y debería poder cruzar ileso. El primer consejo de Sancho es dejar pasar esa parte del hombre que ha dicho la verdad y colgar aquella parte que ha mentido. Pero como entonces habría que cortarlo en dos partes, lo que no funcionaría, él resuelve que dado que las razones para su absolución y condena están en equilibrio en la balanza de la justicia, es mejor dejar que prevalezca la clemencia y dejarlo ir.

El dilema se basa en la famosa paradoja: «Epimenides de Creta dijo: "Todos los cretenses son mentirosos"». ¿Está mintiendo cuando dice eso o no? Se podría desactivar la antinomia definiendo al mentiroso como el que miente a veces. Si se asume que los mentirosos siempre mienten, se podría reafirmar con la frase de Bertrand Russel: «Un hombre dice: "Estoy mintiendo"»"1. Aquí encontramos una auto-referencia que consiste en una afirmación que -en el meta-nivel- dice al mismo tiempo algo sobre este enunciado. Tarski quiere resolver el problema con los lenguajes artificiales, en los que siempre hay una separación entre el metalenguaje y el lenguaje sobre objetos, de modo que dentro del lenguaje sobre objetos no sea posible hacer afirmaciones sobre este lenguaje. Estos le están reservados al metalenguaje ${ }^{12}$.

El enunciado es una de las famosas paradojas lógicas matemáticas, que para el juez Sancho podría ser difícil de entender. Pero como agravante en el presente caso se agrega que verdadero o falso solo puede ser una afirmación sobre el presente o el pasado, pero no la intención de una acción planificada. Una intención puede ser sincera, aún si la acción prevista al final no se lleva a cabo. Es decir, el caminante puede haber tenido sinceramente la intención de ser ahorcado después de cruzar el puente. Esta intención sigue no siendo una mentira, incluso si luego no es ahorcado. Entonces, ¿cuál es la culpabilidad del acusado? No ha cometido perjurio si tenía la sincera intención de ser ahorcado. El juez Sancho no debería haber juzgado con clemencia in dubio pro reo, sino que debería haber aconsejado a sus colegas jueces subordinados una absolución. Y si el caso fuera menos fabuloso y más realista, Sancho también habría tenido que garantizar que se aboliera la práctica ilegal de expiar el perjurio con la pena de muerte. Pero Sancho parece superado con su último caso, aunque este fue como los demás, excepto el penúltimo caso, una broma que le gastaron. Aquí Sancho se encuentra claramente al borde de sus límites intelectuales, como ya anteriormente se había encontrado con los límites de la inercia judicial, la imparcialidad, la igualdad de trato y la objetividad.

Don Quijote aparece con el yelmo de Mambrino al comienzo de nuestras exposiciones y no debe faltar al final. Porque ya durante el informe sobre la actividad de Sancho como juez se introduce un nuevo episodio, el cual continúa luego de su finalización. Esta vez don Quijote tiene que hacer justicia, no como juez, sino en un duelo cuyo resultado determina cuál de las dos partes tiene razón. Como es sabido, en la Edad Media, cuando no había pruebas suficientes, se realizaban duelos para obtener pruebas mediante el juicio de Dios y para probar así que el vencedor tenía razón. Dado que más tarde el duelo se volvió inusual como elemento del juicio,

11. Ver Russell y Whitehead, 1910, p. 63

12. Ver Tarski, 1935, pp. 303-326.

HIPOGRIFO, 7.1, 2019 (pp. 701-711) 
se hicieron más habituales los duelos privados extrajudiciales, a pesar de que habían sido prohibidos por el Concilio de Trento ${ }^{13}$, en los que a la parte victoriosa se le daba la razón. Doña Rodríguez se había dirigido a don Quijote porque su hija había sido abandonada por un rico campesino, que la había seducido después de haber prometido casarse con ella. El duque, quien debía juzgar en este caso, estaba inhabilitado y comprometido, dado que el padre del seductor agresor le habría prestado dinero. Don Quijote, que considera su deber ayudar a los desafortunados y castigar a sus opresores, quiere batirse en duelo con el seductor, aunque este no sea un caballero. El duque, que está preparando el duelo, dice a don Quijote que el oponente se batirá con armadura completa en cuatro días y afirmará que la chica miente cuando dice que él le prometió matrimonio. Quien gane el duelo tiene razón. Sin embargo, el corrupto duque no envió al hijo del rico campesino para no perder su apoyo financiero, sino al lacayo Tosilos. Este se enamora de la chica por la que se supone debe luchar. Cuando él le pide casamiento ella acepta después de una resistencia inicial. El proceso se suspende porque la demandante ha perdido interés en la acusación. La decisión sobre qué parte tiene y recibe la razón resulta innecesaria, así como el duelo. Así que don Quijote quiere luchar por la justicia en un duelo que el duque organiza por su propio interés con su lacayo y no con el acusado, para mantenerse ileso y no perder la protección económica del padre del perpetrador. Queda por ver si el seductor es culpable o no. De todos modos, queda impune. El proceso se diluye, como en el caso del yelmo de Mambrino, donde queda abierto si don Quijote debe ser absuelto como legítimo propietario o condenado como ladrón.

Por último, resumiendo volvamos al trabajo judicial de Sancho. ¿Son sus procedimientos más eficaces que aquellos en los que interviene don Quijote? Es alabado como un juez sabio. ¿Cómo se presentan en él la corte y el proceso del juicio? En el caso de la demanda entre el campesino y el sastre Sancho reconoce correctamente la negligencia contributiva de ambos, pero no reconoce que se contradice con cualquier experiencia de vida que un sastre confeccione dedales en lugar de una capucha, y queda ridículo. En el caso de los ancianos, uno de los cuales es el deudor y el otro el acreedor, la sabiduría de Sancho se demuestra en la búsqueda de evidencias. La comicidad proviene del hecho de que el deudor engaña diciendo la verdad y el juez Sancho se abstiene de castigar el perjurio fraudulento. En el tercer caso, la presunta víctima de violación resulta ser una prostituta estafadora. Esta vez el juez Sancho castiga con razón la falsa declaración deliberada ante el tribunal. En el caso del juego, el juez Sancho no comprueba si el bribón tiene derecho a una propina. Como el importe de la reclamación corresponde al importe del beneficio correspondiente a la estafa, Sancho recompensa el delito de la estafa concediéndole un centenar de reales por concepto de propina. Por lo tanto, en este caso, el tribunal ordena un pago que no es objeto de reclamación judicial y que constituye una recompensa de un fraude.

En los tres últimos casos, el trabajo de Sancho como juez tampoco se manifiesta de manera positiva. En el enfrentamiento de poderes entre juez y acusado, Sancho

13. Ver Strosetzki, 2015. 
solo deja ir al muchacho cuando oye que quiere hacer valer su voluntad y no atentar contra la voluntad judicial de Sancho. Aquí Sancho no conoce ni reglas ni leyes, sino que se muestra poderoso, llevado por sus emociones y arbitrario. En el caso de la chica hermosa y el hermano guapo, comete favoritismo en el cargo y pierde su imparcialidad por sus planes de casar al hermano con su hija Sanchica. Finalmente, en el último caso, no ve que el acusado no cometió perjurio si tenía la sincera intención de ser ahorcado, es decir que merecía una absolución. Aquí Sancho se encuentra claramente al borde de sus límites intelectuales, así como ya anteriormente se había encontrado con los límites de la inercia judicial, la imparcialidad, la igualdad de trato y la objetividad. A pesar de algunos buenos enfoques, el tiempo de ejercicio de Sancho como juez ofrece una imagen satírica de un tribunal inadecuado y de audiencias judiciales impugnables, en lugar de la demostración de una labor ejemplar de un juez sabio e intachable.

\section{BiBLIOgRAFÍA}

Byrne, Susan, Law and History in Cervantes' "Don Quijote», Toronto, University of Toronto Press, 2012.

Cervantes, Miguel de, Don Quijote de la Mancha, ed. Francisco Rico, Madrid, Real Academia Española, 2015.

Chevalier, Maxime, «Lecturas del Quijote, Capítulo XLV», en Miguel de Cervantes, Don Quijote de la Mancha, volumen complementario, ed. Francisco Rico, Madrid, Real Academia Española, 2015, pp. 227-229.

Maravall, José Antonio, Utopía y contrautopía en el «Quijote», Santiago de Compostela, Pico Sacro, 1976.

Montero Reguera, José, El «Quijote» y la crítica contemporánea, Alcalá de Henares, Centro de Estudios Cervantinos, 1997.

Pelorson, Jean-Marc, «Le discours des armes et lettres et l'épisode de Barataria», Les Langues Néo-Latines, CCXII, 1975, pp. 41-58.

Pérez Martínez, Ángel, El buen juicio en el «Quijote»: un estudio desde la idea de la prudencia en los Siglos de Oro, Valencia, Pre-Textos, 2005.

Redondo, Augustin, «Tradición carnavalesca y creación literaria. Del personaje de Sancho Panza al episodio de la Ínsula Barataria en el Quijote», Bulletin Hispanique, LXXX, 1978, pp. 39-70.

Rivero Iglesias, Carmen, «El bien común en el Quijote y el gobierno de Sancho en la ínsula Barataria», en Autoridad y poder en el Siglo de Oro, ed. Ignacio Arellano, Christoph Strosetzki y Edwin Williamson, Madrid/Frankfurt am Main, Iberoamericana/Vervuert, 2009.

Russell, Bertrand, y Alfred N. Whitehead, Principia Mathematica, vol. 1, Cambridge, Cambridge University Press, 1910 
Strosetzki, Christoph, «Lecturas del Quijote», en Miguel de Cervantes, Don Quijote de la Mancha, volumen complementario, ed. Francisco Rico, Madrid, Real Academia Española, 2015, pp. 231-233, 240-241 y 249-252.

Strosetzki, Christoph, «¿Yelmo de Mambrino o bacía de barbero? Parodia y carnavalización de un juicio», Romance Notes, en prensa.

Tarski, Alfred, «Der Wahrheitsbegriff in den formalisierten Sprachen», Studia Philosophica, 1, 1935, pp. 261-405. 